\title{
Los rostros del evemerismo: diálogos misionales entre la Alta Edad Media (s.VI-VIII) y América (s.XVI) ${ }^{1}$
}

\author{
Eduardo Valenzuela Avaca \\ UNIVERSIDAD DE CHILE \\ ejvalena@uc.cl
}

Resumen: A partir del estudio comparado de tres experiencias de la misión histórica -Martín de Braga entre los Suevos (s.vi), la misión de Bonifacio entre los Germanos (s.viII) y los trabajos de Bernardino de Sahagún entre los $\mathrm{Na}$ huas (s.XVI) - el presente estudio se propone indagar en torno a las expresiones históricas de un instrumento polémico de la misión conocido como evemerismo, y que posee como principio hermenéutico la negación del carácter divino de los Dioses por su condición humana. Como hipótesis se sostiene que el evemerismo no se expresa en la misión histórica como un exemplum o narrativa de la misión, sino como un principio teórico susceptible de ser ensamblado de acuerdo a la agenda del misionero y a las posibilidades de su trabajo de campo.

Palabras clave: Misión - Idolatría - Modernidad temprana - América - Europa

Abstract: From the comparative study of three experiences of the historical mission - Martin de Braga among the Suevians, the mission of Bonifacio among the Germans and the works of Bernardino de Sahagún among the Nahuas - the present study intends to investigate around the historical expressions of a polemical instrument of the mission known as euhemerism, whose hermeneutical principle is the negation of the divine character of the Gods by their human condition. As a hypothesis, it is proposed that euhemerism is not expressed in the historical mission as an exemplum or a narrative of the mission, but as a theoretical principle that can be assembled according to the missionary's agenda and the possibilities of his fieldwork.

Keywords: Mission - Idolatry - Early Modernity - America - Europe

1 Este artículo forma parte de los avances del proyecto Postdoctoral Fondecyt No3170037, Las armas del convencimiento: diálogos misionales entre la edad media (s.VI-VIII) y la primera evangelización de América (S.XVI)", desarrollado en la Universidad de Chile bajo el patrocinio de la prof. María Eugenia Góngora. El presente estudio no contó con financiamiento adicional. 


\section{INTRODUCCIÓN}

A lo largo del siglo xvI, cada territorio americano -misionado pacíficamente o abierto por las armas de la conquista - fue el escenario de una misión particular. Si el siglo xv peninsular había tenido como eje la conversión de judíos y musulmanes, en América los primeros encuentros con los naturales de las Islas evidenciaron los rasgos inconfundibles de la idolatría. Si la cristología dominó los trabajos de la misión entre judíos y musulmanes, la evangelización de los gentiles de América necesitó de una fase pre-catequética que la teología de mediados del siglo xx ha dado en llamar kerigma ${ }^{2}$.

Las verdades proclamadas por la evangelización en América comprometen aspectos basales de las culturas misionadas. Por una parte, a través de la narrativa del Génesis se establecerá la arquitectura general del mundo proclamado, proveyendo criterios ontológicos sobre el humano y el no-humano, y una nueva jerarquía de los existentes; por otra, la antigua religión será declarada falsa y sus dioses, sometidos a diversas formas de extirpación, siendo la destrucción física de los ídolos la expresión más evidente de la lucha contra los dioses locales.

Esta respuesta misional de ningún modo se restringe al caso americano. Cada vez que la misión histórica ha identificado las formas de la idolatría en las comunidades evangelizadas, los trabajos de la cristianización han exigido la eliminación de esta idolatría como prerrequisito para la conversión y han debido iniciar los procesos de composición de mundos. Es en esta etapa inicial donde la sacralidad atribuidas a los dioses locales debe ser disputada, no a partir de una damnatio memoriae, sino de la redefinición de estas entidades de acuerdo a los nuevos esquemas proclamados por el kerigma. Diversos serán los recursos a los que se acudirá. La demonología, por ejemplo, será utilizada tanto en la América del siglo Xvi como en experiencias alto-medievales del siglo vi, para redefinir la condición de los dioses de las naciones a partir de una narrativa particular como es el relato de los ángeles caídos ${ }^{3}$. Retóricas sobre la inanidad de los dioses gentiles,

2 E. ValenZuela, "Kerigma: preguntas teóricas en torno a la primera evangelización de América (Antillas, 1510-Nueva España, 1524)”, en Historia Crítica 58 (2015) 13-32 (15).

3 E. Valenzuela, "Mecanismos antiidolátricos en el De Correctione Rusticorum de Martín de Braga: una mirada desde la evangelización temprana de América”, en Nicolás Cruz (ed.), América latina y lo clásico, lo clásico y América latina (Ril Editores, Santiago 2018) 69-90. 
sobre su incapacidad para moverse, hablar o inteligir, serán ensayadas tanto en América como en otras experiencias de evangelización ${ }^{4}$.

En el estudio que se presenta, abordaremos una tercera retórica antiidolátrica conocida comúnmente como evemerismo y que posee como principio polémico la negación del carácter divino de los dioses gentiles en virtud de su condición humana. A partir del estudio comparado de tres experiencias de la misión histórica -Martín de Braga entre los Suevos (s.vi), la misión de Bonifacio entre los Germanos (s.viII) y los trabajos de Bernardino de Sahagún entre los Nahuas (s.xvI), nos proponemos observar las distintas expresiones del evemerismo en la misión histórica comparada. Se sostiene, como hipótesis central, que este recurso polémico no se expresa en la misión kerigmática como un principio polémico flexible, capaz de adaptarse a los distintos escenarios misionales y a las distintas estrategias de cada evangelizador.

\section{ANTECEDENTES}

Convencionalmente, la reducción de las divinidades a la categoría de hombres se encuentra ligada a la figura de Evémero de Messina (siglo IVIII a.C.), uno de los escritores más elusivos y desconcertantes del período helenístico. Aspectos elementales de su biografía como su fecha exacta de nacimiento o los contextos de elaboración de sus obras se nos escapan, y los especialistas continúan abordando a Evémero sin establecer si su producción escritural corresponde a la de un filósofo, un historiador o un teólogo, o si sus escritos fueron guiados por fines políticos o religiosos 5 . Su obra central, la Hiera anágrafe, se encuentra perdida, y todo cuanto sabemos de ella corresponde a referencias indirectas: una traducción al latín -perdida- del poeta Quinto Ennio (239-169 a.C.), cuyos fragmentos reposan en el libro I de las Divinae institutiones de Lactancio (245-325 d.C.), y un sumario contenido en la Bibliotheca historica de Diódoro Sículo (s. I a.C.), cuyo libro VI se conservó como parte de la Preparatio evangelica del obispo Eusebio de

4 En la Saga del Rey Óláfr Tryggwason, compuesta en Islandia por el monje benedictino Oddr Snorrason (s.XII), el devoto rey es reprendido por el rey Valdemar por no temer a los Dioses y éste contesta desde las letras del Antiguo Testamento, el famoso Salmo 115. No tengo miedo de los dioses que adoras, dice, porque no creo en dioses que no ven, no hablan, no escuchan y no poseen razón. Cristopher Abram, "Modeling Religious Experience in Old Norse Conversion Narratives: The Case of Óláfr Tryggvason and Hallfreðr vandræðaskáld”, Speculum 90/1 (January 2015) 114-157 (121).

5 B. Garstad, "Notes and Discussions: Belus in the Sacred History of Euhemerus", en Classical Philology, Vol. 99, No. 3 (2004) 246-257 (246). 
Cesarea (253-339 d.C) ${ }^{6}$. Dicho de otro modo, la obra de Evémero sobrevivió gracias al cristianismo primitivo.

Pese a la importancia que el evemerismo cobrará como instrumento antiidolátrico en las polémicas del cristianismo primitivo, solo cuatro escritores cristianos de origen griego y cuatro de origen latino refieren a Evémero $^{7}$. Ninguno de ellos, sin embargo, leyó la Hiera anágrafe de Evémero ni la traducción latina de Ennio, la Euhemerus sive Sacra historia, descansando en una tradición doxográfica que ponía en relieve los aspectos más secularizantes de su obra ${ }^{8}$. La recepción que el cristianismo primitivo hizo de estas ideas alteró considerablemente los principios en los que la reflexión de Evémero se sustentaba. Mientras los apologetas se concentraron en la idea de una reducción de los Dioses locales a la figura de simples hombres mortales, con el propósito de refutar la divinidad atribuida a ellos y denunciar los cultos paganos como formas impías del culto a la criatura, la Hiera anágrafe exhumó los relatos fundacionales de Urano, Cronos y Zeus como una forma de comprender los procesos asociados al ascenso de seres humanos a la categoría de Dioses?.

Pese a la excepcional recepción de algunas de sus ideas, la Hiera anágrafe no contiene una teoría religiosa que sea particularmente original. Distintos autores precedieron a Evémero tanto en diversos aspectos considerados propios de su obra. Pueden mencionare las obras de Hecateo de Abdera (s.Iv), Leon de Pella (s.Iv) y Megástenes (s.IV-III), especialmente la descripción del viaje de Dionisio por la India presente en la obra de este último ${ }^{10}$,

6 M. WiniarczyK, The Sacred History of Euhemerus of Messene (De Gruyter, Berlin 2013), 13. J.D. Coокe, "Euhemerism: A Mediaeval Interpretation of Classical Paganism", en Speculum, Vol. 2, No. 4 (1927) 396-410 (397)

7 Por los griegos, Teófilo de Antioquía, Clemente de Alejandría, Eusebio de Cesarea y Teodoreto de Ciro; Minucio Félix, Arnobio, Lactancio y Agustín por los latinos.

8 M. WiniarczyK, The Sacred History... 152.

9 La idea de que un humano pudiese ser elevado a la categoría de Dios por actos en beneficio de la comunidad - evergetismo - se encontraba ya presente en la poesía épica de Homero. Siendo la de Evémero una obra helenista, sin duda deben sumarse a este contexto de elaboración tanto el impacto de las conquistas de Alejandro Magno, cuyos relatos de seguro conoció a través de los libros de Onesícrito, Nearcos y Megástenes, así como la influencia de los modos de gobierno de la dinastía Ptolemaica, ambos hitos trascendentales en el fortalecimiento de una idea apoteosis por evergetismo. H. Gamble, "Euhemerism and Christology in Origen: Contra Celsum, III 22-43", en Vigiliae Christianae, Vol. 33, No. 1 (1979) 12-29 (13). T. Brown, "Euhemerus and the Historians", en The Harvard Theological Review, Vol. 39, No. 4 (Oct., 1946) 259-274 (265)

10 T. Brown, "Euhemerus and the Historians...", 265. 
así como la construcción de un núcleo histórico en algunos mitos griegos por parte de Hecateo de Mileto, Helánico de Mitilene (siglo v), Heródoro de Heraclea Póntica (siglo v) y Paléfato (siglo Iv) ${ }^{11}$. La convicción de que algunos héroes podían transformarse en dioses era un hecho bien conocido entre los griegos, quienes veían en los relatos sobre Asclepio, Heracles y los Dioscuros ejemplos concretos de esta divinización, una lista que podía ser complementada con los honores rendidos a los homines pro diis culti como Aquiles, Helena, Ino y Melicertes, entre otros ${ }^{12}$.

Hay un punto, sin embargo, que merece atención. El evemerismo desarrollado por los escritores cristianos de los primeros siglos bebe de una segunda fuente de inspiración, bastante más directa y explícita en su lectura. En el Libro de la Sabiduría de Salomón (c. 37 a.C) se señala que la idolatría ingresó al mundo "por la vanidad de los hombres" (Sab. 14:13) quienes rindieron culto divino a simples seres humanos. En un caso, un padre desconsolado por la muerte de su hijo, el cual elabora una imagen del difunto para adorarle como a divinidad, instituyendo misterios y ritos que serán seguidos por sus subordinados y, posteriormente, convertidos en ley (Sab.14:12-16). También el infame culto a los reyes y, en su ausencia, la adoración de sus estatuas e imágenes (Sab.14:17). Para halagar a los gobernantes, los artistas habrían exagerado la belleza de las imágenes, arrastrando a las masas al culto divino de aquellos a los que poco antes se veneraban solo como hombres (Sab.14:18-20).

Mientras la Hiera Anágrafe utiliza la divinización de los hombres para explicar el origen de los Dioses Olímpicos - una idea utilizada por los apologetas cristianos-, la Sabiduría recurre al mismo recurso, pero para un propósito distinto: establecer los orígenes del culto idolátrico y evidenciar su ilegitimidad. Bajo esta idea, la formulación de una teoría evemerista, tal y como fue desarrollada por los apologetas cristianos en su polémica con el paganismo circundante, puede ser considerada la síntesis de dos momentos exegéticos hasta cierto punto independientes. Por una parte, las reflexiones contenidas tanto en la Sabiduría permitirán a los escritores cristianos integrar esta antigua idea sobre el origen humano de los dioses en el concierto de las expresiones idolátricas de las naciones, dando-progresivamente- un sustento de canonicidad a estas reflexiones. En segundo término, la recepción de la

11 M. Winiarczyk, The Sacred History..., 46.

12 M. Winiarczyk, The Sacred History..., 29. 
Hiera Anágrafe y la inversión de los principios en los que la obra expresó la apoteosis, entregarán a los apologetas una solución a la pregunta por la condición ontológica de las divinidades gentiles, permitiéndoles refutar el carácter divino de los dioses locales y probar la falsedad de sus cultos, precisamente en virtud de su naturaleza humana. Este nuevo recurso, a veces denominado sceptical euhemerism ${ }^{13} \mathrm{o}$ euhemerismus inversus ${ }^{14}$, será acá llamado simplemente evemerismo.

En las próximas páginas abordaremos experiencias de la evangelización donde el evemerismo ha operado como recurso antiidolátrico en la polémica sobre la condición de los dioses de la gentilidad. Estas experiencias, distantes en tiempo y espacio, nos permitirán no solo evidenciar la variabilidad del instrumento en las manos de cada evangelizador, sino también ponderar la continuidad y estabilidad de este recurso a lo largo de siglos de misión. El evemerismo de Bernardino de Sahagún, tercer caso de nuestro estudio, ocurrirá mil años después de los ensayos de Martín de Braga en la Gallaecia del siglo vi d.C.

\section{Atavíos de Reyes: la síntesis de Martín de Braga (s.vi)}

El sermón de Martín de Braga a los Suevos -conocido comúnmente como De Correctione Rusticorum ${ }^{15}$ - constituye una muestra representativa de un género de escritos surgidos en los trabajos de conversión a los gentiles, en el contexto del kerigma. Se trata de un género concebido para trabajar con audiencias que no solo desconocen la buena nueva de Cristo, sino también los fundamentos cosmológicos y ontológicos del mundo proclamado por la evangelización. El misionero debe narrar la creación del mundo, estableciendo la soberanía del Dios único sobre su creación, la especificidad humana en la totalidad de los existentes, y el lugar de los Dioses de las naciones en este mundo proclamado. Al igual que algunos de los escritos más emblemáticos de la primera evangelización América (s.Xvi), será el relato de los ángeles

13 H. Gamble, "Euhemerism and Christology...", 15.

14 J.W. Schippers, De ontwikkeling der Euhemeristische godencritiek in de Christelijke Latijnse literatuur (Utretch, Groningen, 1952) 103.

15 Se le conoce también como Epistola ad Polemium, De origene idolorum (a partir de la descripción del primer capítulo), De Correctione Rusticorum (descriptor utilizado en el antiguo breviario de Braga) y De Castigatione Rusticorum, nombre que recibe en el manuscrito más antiguo de los conservados (Mansc. K). Martín de BRAGA, Sermón contra las supersticiones rurales. (Trad. de Rosario Jove Clols, El Albir, Barcelona 1981) 
caídos el recurso utilizado para establecer su origen y naturaleza. Sin embargo, de forma complementaria a la demonología, Martín de Braga logra integrar la polémica sobre los dioses-humanos en su sermón, y hacer uso de sus posibilidades persuasivas, polémicas, sin renunciar a la condición demoníaca de los dioses. El resultado, una suerte de excursus evemerista al interior de su Sermón, nos presenta nuevas posibilidades de esta hermenéutica en la historia de la misión hacia los gentiles.

La vida del llamado "Apóstol de los suevos" hasta su ingreso en Hispania, el año 550, es de difícil reconstrucción y aun quienes se han dedicado al estudio de esta figura discrepan notoriamente en algunos pasajes, en especial sobre las motivaciones del viaje de Martín. Sabemos que nació en Panonia -“pannoniis Genitus" - en el 520, y que vino a la Gallaecia desde Oriente por mar -"ex Orientis partibus nauigans Galliciam uenit"- de acuerdo a lo dicho por Isidoro de Sevilla ${ }^{16}$, sin embargo, hay orientes distantes y próximos en su extenso viaje.

De acuerdo a Gregorio de Tours, tras dejar la Panonia, el futuro Obispo de Braga viajó hacia el este, visitando lugares sagrados y recibiendo una formación considerada sobresaliente para su tiempo ${ }^{17}$. Como parte de un movimiento migratorio de monjes hacia Egipto, Martín habría llegado a Alejandría, donde -en calidad de monje ortodoxo- habría tenido acceso a las bibliotecas y colecciones de los monasterios de aquella ciudad, lo que explicaría su formación clásica, en tiempos de un emperador Justiniano que intentaba afanosamente purgar de expresiones paganas y heterodoxas la nueva fe unitaria, nicena. Es allí, con toda probabilidad, donde tuvo acceso a las Sententiae Patrum Aegyptorum y a los Canones Ex Orientalium Patrum Synodis que años más tarde, junto a uno de sus discípulos, traduciría al latín. El historiador, poeta y obispo de Poitiers, Venatius Fortunatus (530-600) recordará, años más tarde, haber tenido conversaciones con Martín en torno a Sócrates, Platón, Aristóteles, Crísipo de Solos y Pítaco de Mitilene, así como Hilario de Potiers, Gregorio el Grande, Ambrosio de Milán y Agustín de Hipona, entre otros ${ }^{18}$.

16 Isidoro de Sevilla, De Viris Illustribus (Ed. Univ. Salamanca, Salamanca 1964), Cap. XXII, 145.

17 “...in tantum se litteris imbuit ut nulli secundus sui temporis haberetur". Gregorio De Tours, Historia Francorum (Jacques-Paul Migne [ed.], Patrologia cursus completus. Series Latina, B. 71, 1849). Lib. V, cap. 37.

18 E. KIM, St Martin of Braga: sources for his tolerance toward the rustici in sixth century Galicia 
Existe también un oriente próximo. Gracias a la Historia Francorum sabemos que poco antes de 550, Martín se encontraba en las Galias, concretamente en la capilla de San Martín de Tours, cuando se produjo el arribo de una comitiva desde Gaellecia enviada por el rey Charrarico, considerado como un rey arriano por aquel entonces. Charrarico solicitaba la intercesión milagrosa de San Martín de Tours para sanar a su hijo Theodemir, quien padecía de lepra ${ }^{19}$. La milagrosa recuperación de Theodemir, el envío de reliquias de San Martín de Tours y el ingreso de Martín en la Gaellecia marcarán, al menos simbólicamente, el fin del arrianismo suevo. Durante su breve estancia en las Galias, Martín habría tenido ocasión de conocer y entablar amistad con Venancio Fortunato y con las monjas de San Cesáreo de Arlés $^{20}$, siendo esta última una figura determinante para comprender las estrategias misionales utilizadas por Martín, más tarde, entre los suevos.

Los motivos que impulsaron su viaje a Gaellecia son, sin embargo, sumamente difíciles de precisar, más allá de haber sido un viaje movido por inspiración divina - Divinis nutibus actus -, tal y como el propio Martín escribiese en su epitafio ${ }^{21}$. Mientras J. Sasel considera la llegada de Martín a Gaellecia como parte de un proyecto de restauración político-religiosa de Justiniano - es decir, a Martín como agente de Bizancio-, autores como E. Kim señalan que tanto este viaje como el de Alejandría habrían surgido por la necesidad de encontrar un clima de libertad intelectual en un contexto represivo $^{22}$. A. Ferreiro, por su parte, ha considerado el viaje de Martín a Tours como el de un peregrinaje común a la época ${ }^{23}$, y la elección de Gaellecia como el lugar escogido por Martín para asentarse, estaría relacionado con la

(A thesis for the degree of Master of Arts in religious studies, University of British Columbia, 1992) 17.

19 A. Fontan, "San Martín de Braga: una luz en la penumbra" en Cuadernos de Filología Clásica, Vol. XX (1986-87) 185-199 (193). A. Ferreiro, "Early medieval missionary tactics: the example of Martin and Caesarius" en Studia Historica vol.6 (1988), 225-238 (226).

20 G. DíAz-Díaz, Hombres y documentos de la filosofía española, Vol 5. (Editorial CSIC, Madrid 1995) 240.

21 "Pannoniis genitus, trascendens aequora vasta, Galliciae in gremium divinis nutibus actus". MARTÍN DE BRAGA, Sermón contra las supersticiones rurales..., 7.

22 J. SASEL, "Divinas nutibus actus, Due postille per San Martino Di Bracara", en Historia, 27 (1978) 249-254 (251).

E. Kim, St Martin of Braga: sources for..., 15.

23 A. Ferreiro, "Early medieval missionary...., 227. 
etnicidad que el panonio compartiría con la nación sueva ${ }^{24}$. La discusión es, como se ve, extensa y no podemos ingresar a ella, dado el carácter y los propósitos de este estudio. Nos interesa, de momento, evidenciar que la llegada del Apóstol de los suevos a la Península Ibérica no se encuentra determinada por una misión ad gentes propiamente tal, una idea sobre la que volveremos más adelante.

Es en el año 572 cuando la carrera eclesiástica de Martín de Braga llega a su punto máximo de desarrollo. Tras ser Obispo de Dumio en 556 y secretario del Primer Concilio de Braga en 561, lograba ahora el Obispado de Braga y la presidencia del Segundo Concilio. En este contexto, se había determinado que los religiosos debían llevar adelante acciones para eliminar formas idolátricas y supersticiosas que encontrasen en sus visitas pastorales. Polemio, uno de los asistentes al concilio y Obispo de la ciudad de Astorga, solicitó a Martín de Braga la elaboración de un escrito modelo que pudiese facilitar el cumplimiento de esta disposición conciliar, y este contestará con una epístola de importante extensión y que posteriormente será conocida como De Correctione Rusticorum (en adelante, DCR).

En su carta, Martín de Braga aconseja a Polemio comenzar su exhortación contra la antigua superstición pagana -pristina paganorum superstitione- a partir del relato del principio del mundo, una modalidad expositiva ampliamente utilizada en la primera evangelización de América ${ }^{25}$. Tras haber creado Dios el cielo y la tierra, formó las criaturas espirituales conocidas como ángeles, quienes se alzaron en rebelión contra el creador y fueron convertidos en demonios ${ }^{26}$. La descendencia de Adán y Eva, continúa el relato, olvidó al Dios creador y cometió numerosos crímenes, provocando la ira del creador y su aniquilación. A partir de Noé, la humanidad se volverá a regenerar y habiendo crecido en número comenzaron a adorar a las criaturas, al sol, la luna, las estrellas, al fuego, a los manantiales y al agua subterránea, creyendo que estas cosas no habían sido creadas por Dios para el servicio del hombre -ad usum hominum - sino nacidas por sí mismas ${ }^{27}$.

24 A. Ferreiro, "The westward journey of St. Martin of Braga", en Studia Monastica, 22 (1980) 243-251 (248).

25 E. Valenzuela, "Kerigma...", 29.

26 Martín de Braga, Sermón contra las supersticiones rurales..., t.3, 25

27 Martín de Braga, Sermón contra las supersticiones rurales..., t.5-6, 27 
Es en este punto donde ingresa el evemerismo. Los demonios, observando que la humanidad erraba, dando culto a las criaturas y no al creador, tomaron nombres de hombres y se hicieron adorar. Júpiter se llamó uno de ellos, un mago (magus) disoluto que había cometido graves deshonestidades como tomar por esposa a una hermana-Juno-, corromper a sus hijas Minerva y Venus, y mancillar con incesto a sus nietas y a su familia. Marte fue responsable de litigios y discordias, y Mercurio, inventor de todo tipo de hurtos y fraudes, considerado un dios por hombres codiciosos. Saturno se hizo llamar otro que viviendo en todo tipo de crueldades devoraba a sus propios hijos, y Venus -mulier meretrix- se prostituyó no solo con innumerables hombres sino también con su padre Júpiter y con su hermano Marte $^{28}$. A diferencia -como veremos- de Bernardino de Sahagún y de Bonifacio, Martín de Braga integra el evemerismo como un recurso auxiliar. No solo intenta una doble definición de los dioses locales sino que hace del evemerismo un recurso instrumental para los propios demonios. He aquí, finaliza Martín de Braga, "cómo fueron en aquel tiempo aquellos hombres depravados [perditi homines] a quienes los ignorantes campesinos [rustici] honraban gracias a sus detestables engaños" y "cuyos nombres se pusieron los demonios para que les adorasen como a dioses"29.

Aunque la elegante incorporación del recurso evemerista a la teoría demonológica hace de este un instrumento misional particularmente interesante, cabría preguntarse si a través de este sermón la solicitud de Polemio de Astorga fue satisfecha. A diferencia de los visigodos - señala Ferreiro- los suevos nunca tuvieron un contacto prolongado con la cultura romana nunca fueron foedatari del Imperio- y la romanización penetró de manera descendente, desde la aristocracia hacia los rustici ${ }^{30}$. Pese a ello, y a diferencia de otros sermones kerigmáticos como la prédica de Wessobrunn (c. 790) compuesta en vetero-altoalemán- o los ya mencionados textos tempranos de América, compuestos en lenguas americanas, Martín de Braga escribió su $D C R$ en latín. Aunque siempre existe la posibilidad, como apunta A. Ferreiro, de que la obra no estuviese realmente dirigida a los rustici sino a los aristócratas de la nación sueva, lo cierto es que Martín había contado con el apoyo irrestricto de Charrarico, de Theodemir y aun del hijo de este -el rey

28 Martín de Braga, Sermón contra las supersticiones rurales..., t.7, 29.

29 Martín de Braga, Sermón contra las supersticiones rurales..., t.8, 29.

30 A. Ferreiro, "Saint Martin of Braga and Germanic languages: an addendum to recent research", en Peritia 6-7 (1987-1988) 298-306 (299). 
Miro- llamado por Martín "Gloriosissimo ac tranquillissimo et insigni catholicae”, a quien dedicó su obra más influyente, la Formula Vita Honestae ${ }^{31}$.

La pregunta por la inclusión de divinidades como Júpiter, Marte, Mercurio, Venus o Saturno es, en este sentido, pertinente. No solo el DCR omite toda referencia a divinidades centrales del panteón germánico como Óðinn/Wōden, Týr/Tiwwaz y Pórr/ponar sino que el propio Martín de Braga no tiene inconvenientes en reconocer que todos los hombres detestables e infames mencionados en su sermón correctivo a los suevos pertenecían a la nación de los griegos (fuerunt homines pessimi et scelerati in gente graecorum $^{32}$ ). Por su parte, el paganismo previo al advenimiento de los suevos tampoco es integrado o enfrentado en la obra: sabemos que divinidades como Endovellicus recibían culto cerca de la ciudad de Ebora, mientras que las montańas y ríos próximos a la propia ciudad de Braga habían sido lugar de culto para deidades como Decertius, Tomeobrigus y Durbeicus ${ }^{33}$.

Para Martín de Braga la misión a los gentiles suevos no parece haber sido prioritaria. De su abundante producción, el De Correctione Rusticorum constituye su único aporte al problema de la misión ad gentes ${ }^{34}$, y aún este mismo escrito no fue redactado sino a petición del Obispo de Astorga. El evemerismo de Martín de Braga no se encuentra construido a partir del problema idolátrico suevo sino, aparentemente, a partir de una querella particular. Ocho años antes de la peregrinación de Martín a las Galias, fallecía Cesáreo de Arlés (470-542), figura de notoria influencia en el período. Encontramos en su copiosa obra un vasto conjunto de Sermones -alrededor de 250 escritos- destinados a los más diversos propósitos, desde la organización monástica interna hasta la pastoral anti-pagana. En el Sermón 193, Cesáreo se enfrenta a las mismas divinidades señaladas

31 A. Ferreiro, "Early medieval missionary...", 230. A. Fontan, "San Martín de Braga..., 192.

32 Martín de Braga, Sermón contra las supersticiones rurales..., t.8, 30.

33 E. Kim, St Martin of Braga..., 26-27.

34 En el resto de su producción escritural encontramos dos traducciones de obras griegas (Sententiae Patrum Aegyptorum y Canones Ex Orientalium Patrum Synodis), cinco tratados morales (Pro Repellenda Iactantia, Item de Superbia, Exhortatio Humilitatis, De Ira y Formula Vitae Honestae), dos trabajos doctrinales sobre liturgia (De Trina Mersione y De Pascha), tres poemas (In Basilica, para la Iglesia de Martín de Tours; In Refectorio, una inscripción en su monasterio; y su conocido Epitaphium) además de los dos Concilios de Braga. Con la excepción del De Correctione Rusticorum, no hay otros escritos destinados a la evangelización. J.W. Retrig, The Latinity of Martin of Braga (Dissertation presented for the Degree Doctor of Philosophy in the Graduate School of the Ohio State University, 1963) 8. 
por el $D C R$, y a partir del mismo recurso evemerista. Así, Mercurio fue "un hombre miserable, avaricioso, cruel y orgullo", Venus tenida como "la más desvergonzada ramera”, y similar tratamiento tienen Júpiter, Marte y Saturno, no con el propósito de enfrentarse a un panteón activo sino a desarrollar una polémica particular: algunos, dice el Sermón, caen en el error de tributar "honores al Sol, la Luna, Marte, Mercurio, Jueves, Venus o Saturno", consagrándoles los días de la semana, y honrándolos por sus nombres ${ }^{35}$. Son, en efecto, las mismas divinidades señaladas por Martín de Braga en su DCR y precisamente por la misma querella sobre los días y el problema de las vanas observancias ${ }^{36}$.

\section{Los Dioses engendrados: Bonifacio y la Carta de Daniel de Winchester (s.VIII)}

Siendo uno de los más reconocidos misioneros del siglo virI y posiblemente el de mayor influencia en la cristiandad europea de la época, resulta sorprendente la escasa información que tenemos sobre los fundamentos que sostuvieron la misión de Bonifacio - Wynfrith- a los Germanos. Es cierto que en la vida de este religioso la conversión de los paganos al cristianismo constituye solo uno de sus momentos, y que buena parte de sus días estuvieron consagrados a la organización de la Iglesia en Germania, a la reforma de la Iglesia franca y sus trabajos de recristianización en Turingia y Hesse ${ }^{37}$. Sin embargo, es la conversión de los gentiles lo que impulsa al joven Wynfrith a dejar su tierra natal y encaminarse hacia Frisia, lugar donde morirá en martirio años más tarde.

Nacido cerca de Exeter en torno al año 675, Bonifacio -Wynfrith por aquel entonces- ingresó al monasterio de Ad-Escancastre (Exeter) y luego al monasterio benedictino de Nhutscelle (Nursling), en las cercanías de Winchester, bajo el tutelaje del abad Winberht. Allí, de acuerdo a la Vita Bonifacii, habría aprendido el arte de la gramática y las métricas con notable elocuencia, así como la exposición llana de la Historia Universal y en la llamada triple interpretación del conocimiento espiritual (tropología, alegoría, y anagogía). Su dominio de las Sagradas Escrituras era importante,

35 Caesarius of Arles, Sermons, (Catholic University of America Press, Washington 1973), Sermo 193, 33-34.

36 Martín de Braga, Sermón contra las supersticiones rurales..., t.8-9, 31.

37 C.H. Тацвот, "St Boniface and the German mission", en C. J. Cuming (ed.), The Mission of the Church and the Propagation of the Faith (Cambridge University Press, 1970) 45-58 (45). 
y tempranamente había sido maestro en las tradiciones de los Padres de la Iglesia, instruyendo en aquel entonces a otros monjes jóvenes del mismo monasterio $^{38}$.

La carrera misional de Bonifacio comenzó el año 719, cuando se unió a las labores de Willibrord en Frisia. Este último había sido enviado por Egbert de Northumbria el año 690, junto a once compańeros, para realizar labores de evangelización solicitadas por Pipino El Joven, mayordomo de palacio de los Francos, quien había conquistado los territorios de la otra ribera del Rin y podía entregar ciertas seguridades para el trabajo de los religiosos $^{39}$. Sin embargo, para el año 719, la situación había cambiado. La intensa destrucción de templos e ídolos emprendida por Willibrord y sus compañeros había provocado la animadversión de los frisios, quienes se resistían a aceptar la nueva religión. Tras la muerte de Pipino, el año 714, el rey frisio Radbod inició una revuelta política que trajo consigo no solo la persecución y expulsión de los misioneros de Frisia sino también la restauración de los cultos tradicionales ${ }^{40}$. Bonifacio, que en aquel momento aún conservaba su etnónimo -Wynfrith-, misionó por escaso tiempo en aquella tierra estéril, y asistió a un atribulado Willibrord.

La misión en la tierra estéril de Frisia fue, pues, de escaso éxito, y aun la Vita Bonifacii no esconde este hecho. Su retorno invernal a Exeter no es presentado como una huida, ciertamente, aunque tampoco como un fracaso. Es una singular cualidad de los santos, señala el autor, poder percibir cuando sus trabajos no tendrán frutos, y se retiran hacia lugares donde su trabajo pueda ser prolífico ${ }^{41}$. No hay propósito, dirá la Vita, para habitar en un lugar donde el fruto de lo sagrado escasea. Tras un año de esfuerzos por desarraigar la idolatría local, Bonifacio dejó Frisia y volvió a su tierra natal en un intempestivo viaje de invierno.

38 Vita Bonifacii auctore Willibaldi (Impensis bibliopolii Hahniani, Hannover 1905), Cap. II, 9-10.

39 C.J. Broer - M.W. Bruijn, "Bonifatius en de Utrechtse kerk" en E.S.C Erkelens-ButtinGER (ed.), De kerk en de Nederlanden: archieven, instellingen, samenleving (Verloren, Hilversum 1997) 43-65 (44).

40 "'...] prius in Fresia subiectae erant imperio, Redbodi incumbente persecutione ac servorum Dei facta expulsione, vastata erat ac destructa, idulorum quoque cultura exstructis dilubrorum fanis lugubriter renovata... "Vita Bonifacii..., Cap. IV, 16.

41 "[...] dum ad tempus suum sine spiritalis virore germinis laborem minime pollentem perspiciunt..." Vita Bonifacii..., Cap. IV, 17. 
Como apunta Talbot, Bonifacio había aprendido valiosas lecciones de este primer intento. En primer término, resultaba evidente que sin una autoridad oficial respaldando las misiones, sin credenciales y fuentes de autoridad precisas, sin un propósito concreto y una delimitación del campo de actividad, la misión no podría ser llevada adelante. Segundo, que más allá de las formas de misión itinerantes, resultaba fundamental el establecimiento de una misión permanente en el territorio ${ }^{42}$. Y tal cosa, notoriamente, exige que los religiosos sean amparados por un imperium que les permita no solo plantar la semilla del evangelio, sino también remover las raíces de los ídolos o desplomarlos, como hiciese Willibrord en Frisia, o hará Bonifacio en Hesse. El proyecto solo podía sostenerse bajo el manto protector de reinos cristianos y la sujeción de las armas.

Cuando el invierno comenzó a retroceder, Bonifacio resolvió viajar a Roma, llevando consigo las Cartas de Introducción que le hiciese llegar el obispo de su diócesis, Daniel de Winchester ${ }^{43}$. Este, un preparadísimo religioso, había sido alumno del irlandés Maildubh, y uno especialmente activo, enérgico e influente. Vir in multis strenuissimus de acuerdo a lo retratado por la Vita S. Aldhelmi ${ }^{44}$. Beda, que lo tuvo como informante para la elaboración de su Historia, describía a Daniel y a Adhelm como instruidos en asuntos eclesiásticos y en el conocimiento de las Escrituras $^{45}$. En Roma, Bonifacio consiguió de Gregorio II amplias prerrogativas, pudiendo predicar a cualquier nación que encontrase sumida en los errores del paganismo y solo con la condición de enseñar lo contenido en el Antiguo y Nuevo Testamento, de mantener las doctrinas de la Iglesia y de llevar adelante su empresa de acuerdo a las formas eclesiásticas convenidas ${ }^{46}$.

Es en esta segunda etapa de su trabajo misional donde queremos centrar nuestra atención. Tras realizar una fugaz visita a Turingia, Bonifacio ingresó a las Galias junto a sus colaboradores, recibiéndoles la noticia

42 C.Н. Тацвот, “St Boniface and the German mission...”, 46.

43 Vita Bonifacii..., Cap. V, 48.

44 John Allen Giles, Sancti Aldhelmi ex Abbate Malmesburiensi Episcopi Schireburnensis Opera quae extant: comnia e codicibus MSS emendavit (Johannes Henricus Parker, Oxford 1844), Cap. IIII, 368.

45 "ambo et in rebus ecclesiasticis, et in scientia Scripturarum sufficienter instructi" BEDA: Historia ecclesiastica gentis Anglorum (E typographeo Clarendoniano, 1881) Cap. XVIII, 329.

46 С.Н. Тацвот, "St Boniface and the German mission...”, 47. 
de la muerte del rey Radbod (719). Con regocijo y gran alegría, señala la Vita, Bonifacio se puso en marcha hacia Frisia, tierras que para el autor habían dejado de ser yermas - "Barren lands"- y tomaban las formas de algo potencial: tierras sin cultivar ${ }^{47}$. El glorioso Duque Carlos, hijo ilegítimo de Pipino el Joven había establecido la soberanía de los francos sobre Frisia, y el momento para la misión era propicio: las palabras sagradas, dice la Vita, sonaron como trompetas de guerra y las voces de los predicadores atronaron desde el cielo. Durante tres años (719-722) Bonifacio acompañó al arzobispo Willibrord en su misión kerigmática, destruyendo templos y santuarios, construyendo iglesias y adoratorios ${ }^{48}$.

Sin demorarse en Frisia, Bonifacio inició el trabajo encomendado por el Papa, trabajando por primera vez solo en distintos lugares de Germania. En Amanaburch (Amöneburg) corrigió el cristianismo heterodoxo e idolátrico que incentivaban -de buena fe- los reyes cristianos hermanos Dettic y Deorulf, y realizó similares trabajos en la frontera de los Sajones donde pudo rescatar a numerosos hessianos del culto a los ídolos. En aquel entonces, cuando de acuerdo a la Vita cientos de paganos habían abandonado sus errores, Bonifacio viajará por segunda vez a Roma, trayendo consigo no solo informaciones sobre el establecimiento de una iglesia permanente, sino con una carta papal donde los trabajos del Obispo Bonifacio se realizarían bajo la protección y cuidado del glorioso duque Carlos Martel $^{49}$. A su retorno, viajará hacia la frontera de Sajonia para misionar intensivamente a los hessianos, y el año 724 se encontrará en condiciones de llevar adelante episodios de extirpación como la famosa destrucción del roble sagrado de Gaesmere, llamado Roble de Donar-Thor (Fórr) o Roble de Jovis, en las formas de romanizadas. Es precisamente por estas fechas -en torno al año 724- que el viejo Daniel de Winchester escribe a su recomendado, movido por "afecto y buena voluntad", para entregar a Bonifacio nuevas ayudas. Esta vez, no a través de Cartas de Introducción sino de instrumentos para efectivamente superar el problema de la resistencia a la conversión por parte de las comunidades, las "gentes bárbaras" ${ }^{50}$. No será el último en aconsejar a

47 "ad incultas caelesti praedicatione terras pervenit" Willibald, The life of St. Boniface..., Cap. V, 23.

48 Vita Bonifacii..., Cap. V, 23.

49 Vita Bonifacii..., Cap. VI, 29-30.

50 "Bishop Daniel of Winchester Advises Boniface on the Method of Converting The Heathen (723-4)", En C.H. Тацвот, The Anglo-Saxon Missionaries in Germany, Being the Lives 
Bonifacio en su misión hacia los germanos ${ }^{51}$.

Daniel habla sin ambages de "alivianar la pobreza" de los trabajos misionales en tierras paganas, en tiempos en que la misión de Bonifacio -al menos, desde la mirada de la Vita Bonifacii- se encontraba en una inmejorable posición: no solo había recibido un nuevo respaldo del papado -materializado en la protección que le otorgará el Reino Franco para sus labores misionales- sino también en sus incursiones de re-cristianización en Germania, donde había logrado rescatar cientos de almas. Aunque posiblemente el modo de conversión propuesto por Daniel estaba destinado a colaborar en las dificultades de Bonifacio en Frisia -Daniel conocía en detalle aquella experiencia-, la carta adopta las formas de un instrumento abierto, carente de especificidades, susceptible de ser adaptado a distintos escenarios de evangelización y, más importante aún, a solventar una necesidad de la misión de Bonifacio. Remover la idolatría, pero desde las raíces.

No comiences, aconseja Daniel, argumentando en contra de la genealogía de sus falsos Dioses. Aceptando la idea de que estos fueron engendrados por unión sexual, es decir, que hay Dioses padres, madres, hermanos, e hijos, entonces los gentiles se verán obligados a admitir que estos fueron nacidos hombres -humanos- y por ende no pueden ser dioses. A diferencia del evemerismo ensamblado por Martín de Braga en su De Correctione Rusticorum, la propuesta de Daniel de Winchester no tendrá por objeto evidenciar la naturaleza pecaminosa e indigna de los panteones locales, sino insistir en su condición mortal y temporal, a partir de una clara línea argumentativa.

El misionero debe lograr que las comunidades admitan que sus dioses seres humanos -tuvieron un origen, y fueron engendrados por alguien más. Si las audiencias aceptan que el universo tuvo un inicio -como es sostenido por la cosmogonía del Antiguo Testamento-, entonces los falsos Dioses no podrían haber habitado antes de la creación; si los gentiles mantuviesen su idea de un mundo eterno, sin inicio, el misionero debe refutar esta idea con

of SS. Willibrord, Boniface, Leoba and Lebuin together with the Hodoepericon of St. Willibald and a selection from the correspondence of St. Boniface (Sheed and Ward, Londres 1954) 75-79.

51 Es sabido que Eadburga, abadesa de Minster-in-Thanet, envió libros fundamentales para apoyar la misión de Bonifacio y se conservan las cartas con que este agradeció a Eadburga "haber consolado (...) con el regalo de libros sagrados a un exiliado en Germania”. A. ВEACH, Women as Scribes: Book Production and Monastic Reform in Twelfth-Century Bavaria (Cambridge University Press, 2004) 14. 
pruebas convincentes y seguir adelante en su exposición. De lo que se trata es de establecer una brecha entre el Dios verdadero, entidad que preexiste al universo y lo origina, y los falsos Dioses, que por su naturaleza humana pertenecen al mundo y son criaturas del Dios único. A partir de este núcleo, Daniel insta a Bonifacio a continuar la línea argumentativa, forzando a las audiencias a reconocer las contradicciones de sus cosmologías y las inconsistencias del panteón de dioses que las sostienen, la cual debe ser llevada adelante con calma y moderación.

En las manos de Daniel de Winchester, la hermenéutica evemerista permitirá a Bonifacio enfrentar a los bárbaros reacios a la conversión, como los Frisones, a partir del establecimiento de la soberanía del Dios creador y, por extensión, de la cristiandad. Mientras el cristianismo, heredero de Roma, ostenta la riqueza del aceite y el vino, los dioses paganos tienen las tierras yermas sobre las que trabajan los misioneros, las tierras congeladas del norte ${ }^{52}$. Esta es la conclusión que Bonifacio deberá exponer a sus audiencias. De otra manera, ¿cómo dioses omnipotentes, benéficos y justos, podrían haber perdonado a los cristianos que tumbaron los ídolos y alejaron a las naciones de su culto, por todo el orbe ${ }^{53}$.

\section{Reyes sin genealogía, Dioses sin mito: Bernardino de Sahagún y la His- TORIA GENERAL (S.XVI)}

En torno a 1558, Bernardino de Sahagún recibía la tarea de llevar adelante una investigación sistemática sobre la cultura náhuatl, y la composición de instrumentos adecuados para la propagación de la fe entre las comunidades indígenas de Nueva España ${ }^{54}$, con amplias prerrogativas ${ }^{55}$.

El franciscano no necesitaba improvisar. Desde su llegada a Nueva España en 1529, Sahagún había tomado contacto con los frailes más antiguos

52 Bishop Daniel of Winchester Advises Boniface..., 77.

53 "This conclusion also must be drawn: If the gods are omnipotent, beneficent and just, they must reward their devotees and punish those who despise them. Why then, if they act thus in temporal affairs, do they spare the Christians who cast down their idols and turn away from their worship the inhabitants of practically the entire globe?" Bishop Daniel of Winchester Advises Boniface..., 77

54 Bernardino de Sahagún, Primeros Memoriales (University of Oklahoma Press, Oklahoma 1997) 3.

55 Bernardino de Sahagún, Historia general de las cosas de Nueva España (Editorial Porrúa, México 2006) Lib. II, Prólogo, 71. 
de México nutriéndose de las experiencias misioneras que estos habían recabado en los años de prédica, trabajo en los que destacaba la obra fundacional de los llamados Doce Apóstoles de Nueva España. Entre 1530 y 1532 fue Guardián del Convento de Tlalmanalco, a la sombra de los volcanes sagrados Popocatépetl e Iztactépetl, de intensa actividad religiosa, y cuya cima ascendió en busca de formas idolátricas que desarraigar ${ }^{56}$. En 1535, siendo Guardián de Convento de Xochimilco, tuvo ocasión de enfrentar el culto a Tláloc, sumergiéndose en las aguas de una fuente en Xochimilco para remover un ídolo del Señor de la Lluvia, y reemplazando al dios quebrantado por la $\mathrm{cruz}^{57}$. Entre 1536 y 1540, durante su primera estancia en el Colegio de Tlatelolco, Sahagún tuvo la oportunidad de intercambiar experiencias con Andrés de Olmos quien ya desde 1533 realizaba labores de investigación, bajo la solicitud de Martín de Valencia, líder de los Doce Apóstoles francis$\operatorname{canos}^{58}$. Como señala Ángel Ma. Garibay, ya para 1547 -es decir, casi diez años antes del mandato de Francisco de Toral- Sahagún contaba con una importante recopilación de textos escritos que podrían considerarse los materiales iniciales de lo que será su obra central: la Historia General [Universal] de las cosas de Nueva España ${ }^{59}$.

Entre las informaciones más antiguas recabadas por Sahagún y su equipo durante su residencia en el pueblo de Tepepulco, se encuentra un conjunto de veinte "himnos" o "cantos" sagrados de los nahuas, considerados por los especialistas como piezas clave en la comprensión de las formas antiguas en que los mexicas se relacionaban con sus divinidades ${ }^{60}$. El primero de estos cantares estaba consagrado a Huitzilopochtli, el "colibrí de la izquierda del sol (del sur)", divinidad tutelar de la ciudad de México, asociada con el sol, el fuego y el linaje gobernante. Siendo esta una divinidad reciente en Mesoamérica, su relato de origen le permite encontrar su lugar junto a divinidades arcaicas. Su nacimiento se encuentra asociado a un episodio de lucha cósmica en el que los llamados “400 hijos" -Centzon Huitznahua- y la diosa

56 M. León-Portilla, Bernardino de Sahagún. Pionero de la antropología (Instituto de Investigaciones Históricas UNAM, México 1999) 75-76.

57 M. León-Portilla, Bernardino de Sahagún. Pionero de la antropología..., 77.

58 M. León-Portilla, De la Oralidad y los Códices a la Historia General, Génesis del Códice Florentino de Bernardino de Sahagún. (Libros más cultura, México 2001) 68.

59 M.A. Garibay, Historia de la literatura nábuatl, Tomo II (Editorial Porrúa, México 1953-54) 65-67.

60 Eduard Seler, "Los cantos religiosos de los antiguos mexicanos", en Estudios de cultura náhuatl 47, enero-junio de (2014) 254-336 (255). 
Coyolxauhqui, hermana de Huitzilopochtli, asesinan a la madre, Coatlicue. Del cuerpo de Coatlicue emergió Huitzilopochtli, plenamente formado y blandiendo la Xiuhcoatl o "serpiente de fuego", con la cual desmembró a su media-hermana Coyolxauhqui y exterminó a gran parte de los "400 hijos". Esta batalla, que probablemente marca el ocaso de una antigua diosa lunar de la fertilidad como Coyolxauhqui y el ascenso de un joven y heroico dios solar del linaje gobernante ${ }^{61}$, y los atributos asociados al poderío y regencia de esta divinidad, son aspectos retratados con vívidos caracteres en el primer himno nahua registrado por Sahagún (1558-1561) ${ }^{62}$.

En contraste con este registro, los Memoriales en Tres Columnas-compuestos pocos ańos más tarde-comienzan a presentar a la divinidad tutelar nahua como "solo un macehual" (çan maceualli), solo un hombre mortal (çan tlacatl catca), un "hechicero" (naualli) que engaña a la gente con visiones $^{63}$. Los ensayos de estos Memoriales serán recogidos en su obra más conocida, la Historia General, síntesis de sus experiencias en cada espacio misional. Allí, el franciscano abordará a Huitzilopochtli, dedicando el primer capítulo del primer libro a la solución de su naturaleza. Inicialmente es descrito como un dios "robustísimo, de grandes fuerzas y muy belicoso", famoso como destructor de pueblos y "matador de gentes", e incluso parece ostentar ciertas potencias sobrehumanas, como el hecho de parecer "fuego vivo" en el campo de batalla, o portar como divisa "una cabeza de dragón muy espantable que echaba fuego por la boca". Sin embargo, esta primera descripción será acompañada de una clarificación que diluirá cualquier atisbo de divinidad que el joven dios pudiese tener, siguiendo la línea de lo experimentado en Tlatelolco: "A este hombre, por su fortaleza y destreza en la guerra, le tuvieron en mucho los mexicanos cuando vivía. Después que murió le honraron como a dios". La aparente incongruencia entre estos atributos quedará subsanada a partir de una solución razonable: Huitzilopochtli era un "nigromantico o embaidor" 64.

Bajo este modelo, Chicomecóatl era diosa de los "mantenimientos", de aquello que se come y se bebe, porque "debio esta mujer ser la primera que

61 M. Miller - K. Taube, The gods and symbols of ancient Mexico and the Maya: an illustrated dictionary of Mesoamerican religion (Thames and Hudson, London 1993) 94.

62 Eduard Seler, "Los cantos religiosos...”, 257-258.

63 Eduard Seler, "Los cantos religiosos...”, 260.

64 Bernardino de Sahagún, Historia general..., Lib., Cap. I, 29. 
comenzó a hacer pan y otros manjares guisados" ${ }^{65}$. También Tzaputlatena, fue divinizada por el hecho de ser "la primera que inventó la resina que se llama úxitl", un aceite extraído de la resina del pino que "aprovecha para sanar muchas enfermedades" "6 . La dignidad del culto dado a Opochtli se debía al hecho de que fue este hombre quien había inventado "las redes para pescar peces", "los lazos para matar las aves", y "los remos para remar"67, mientras que Nappatecuhtli había inventado "el arte de hacer esteras" con las que eran elaborados los petates y los icpales, y "por eso lo adoran por dios los de este oficio que hacen esteras" 68 . Otra divinidad asociada a los gremios es Yacatecuhtli, dios de los mercaderes, quien habría sido el hombre que comenzó los tratos comerciales y la venta de mercaderías entre las comunidades locales, y "ansí los mercaderes le tomaron por dios y le honraban de diversas maneras" 69 .

Al redefinir a las divinidades americanas - nahuas en concreto- como reyes virtuosos o como hombres y mujeres que habrían contribuido a sus comunidades en la enseñanza de las artes mecánicas o en el oficio de la guerra, Sahagún disputa la autoridad del mito para reposicionar estas figuras en un horizonte histórico, de acuerdo a los modos convencionales de la historia europea. Aunque podríamos sentirnos inclinados a ver en esto una forma de historización, lo cierto es que el desplazamiento de las divinidades desde una condición de origen donde difícilmente pueden ser ubicados en términos de una historia lineal -el mito- no se da hacia la historia sino hacia el pasado. Más allá de los intentos de Bartolomé de las Casas por asociar a algunos dioses mexicanos con ciudades/comunidades de origen ${ }^{70}$, los evangelizadores no tienen interés en relacionar a estos

65 Bernardino de Sahagún, Historia general..., Lib. I, Cap. VII, 31.

66 Bernardino de Sahagún, Historia general..., Lib. I, Cap. IX, 32.

67 Bernardino de Sahagún, Historia general..., Lib. I, Cap. XVII, 42.

68 Bernardino de Sahagún, Historia general..., Lib. I, Cap. XX, 46.

69 Bernardino de Sahagún, Historia general..., Lib. I, Cap. XIX, 43-44.

70 Aunque el mecanismo ocupa varias páginas en la Apologética Historia Sumaria, su aplicación a las divinidades mexicanas es visiblemente menos sistemática que la de Sahagún. Concentrado en el caso mexicano, Las Casas aborda al fundador Huizilopochtli, "el que primero puso por sobrenombre a México theonustitlán", gran capitán y esforzado guerrero; a Camaxtli, edificador y señor de Taxcala, "gran cazador, del cual fingen que tiraba una saeta con su arco hacia el cielo y que de la ida y vuelta que hacía la saeta mataba gran número de aves y animales, de que mantenía toda su gente" y a Quetzalcoatl, un hombre venido de Yucatán a la ciudad de Cholola, "blanco, crecido de cuerpo, ancha la frente, los ojos grandes, los cabellos largos y negros, la barba grande y redonda”. BARTOLOMÉ DE LAS CASAS, Apologética Historia Sumaria, (Universidad Nacional Autónoma de México, México 1967) cap. 122, 644. 
héroes y señores locales -los antiguos dioses- con los linajes locales que tanto los impulsores del régimen colonial como las propias comunidades se empeñan en construir.

La dislocación de las divinidades desde el contexto vivo del mito tampoco estará destinada a la construcción de mitografías en el espíritu de las obras contemporáneas en Europa. No veremos a los teólogos americanos intentar dar densidad a los relatos míticos de estas nuevas divinidades paganas a partir del establecimiento de genealogías o linajes de dioses complejas a la manera de obras como la Genealogía de los Dioses (1482) de Boccaccio, la Historia de los Dioses de los Gentiles de Lilio Gregorio Giraldi (1548), las Imágenes de los Dioses de los Antiguos de Cartari (1556) o las Mythologiae de Natale Conti (1567), cuya existencia conocían. No encontraremos nada similar a las preocupaciones de Alonso de Madrigal "el Tostado" por encontrar un padre para Apolo o la puntillista descripción de los treintaicinco hijos de Neptuno, tal y como figuran en su Libro de las diez questiones vulgares propuestas al Tostado (1507). Se trata de una precaución razonable: a diferencia de las divinidades greco-latinas mitografiadas en Europa, las divinidades americanas persistían más allá de las formas artísticas o la alegoría.

\section{Conclusiones}

Las expresiones del evemerismo en la misión histórica son dispares, y no presentan patrones narrativos o motivos retóricos comunes. La lenta y cuidada historización de divinidades nahuas emprendida por Bernardino de Sahagún en el libro I de su Historia General, se mueve en la dirección inversa al evemerismo recomendado por Daniel de Winchester a Bonifacio, aquel que debe evadir toda cuestión genealógica sobre los falsos Dioses, y concentrar sus esfuerzos en probar la inconsistencia de la reproducción de los Dioses y, luego, a su impotencia en tanto criaturas del Dios único. Martín de Braga, la más antigua de las experiencias misionales analizadas, desarrolla un evemerismo sumamente imbricado. Utilizando la demonología para explicar la naturaleza de las divinidades greco-latinas -camino inevitable al comenzar su obra con el Génesis-, el De Correctione Rusticorum hará uso del evemerismo para llevar adelante una polémica en torno al carácter inmoral y degradado de los dioses romanos. Tres ensamblajes de un mismo principio anti-idolátrico, moldeados cada uno de ellos por los rigores del trabajo misional y las estrategias del misionero. Mil años después de la misión de 
Martín de Braga, las escrituras de Bernardino de Sahagún evidencian el rol preponderante del Antiguo Testamento en la composición de estos recursos polémicos. En su Historia General, Sahagún insertará pasajes completos de la Sabiduría de Salomón, y encargará su traducción al náhuatl para ser utilizado directamente en los trabajos de la misión.

La pregunta por la relación entre recursos anti-idolátricos como el evemerismo y la concreción de estos en instrumentos misionales, es extensa y estimulante. Para el caso americano, sabemos que Bartolomé de las Casas y José de Acosta hicieron uso de este recurso en obras no misionales - Apologética Historia y De Procuranda Indorum Salute-, y en ambos casos las expresiones del evemerismo difieren de los casos arriba estudiados. Igualmente sabemos que los ensayos evemeristas de Sahagún tuvieron como correlato un programa iconográfico, visible en el traslado de los Primeros Memoriales (1558-1561) al Códice Florentino (1578-1580), donde fueron representadas las divinidades centrales del panteón mesoamericano en forma humana de carácter naturalista. El cruce de estos datos con las expresiones alto-medievales proveerá nuevos materiales de análisis, para continuar observando las condiciones que precipitan la aparición del evemerismo y las formas que adopta en cada experiencia misional.

La lucha contra la idolatría, presente en la fase kerigmática de la misión a los gentiles, constituye un antecedente vital para comprender las formas históricas de la evangelización. El quebrantamiento de los ídolos, sabido es, constituye solo una expresión del esfuerzo anti-idolátrico necesario para preparar la conversión. La extirpación profunda señala Gerónimo de Mendieta para el caso americano, se distingue de la destrucción superficial llevada a adelante por los conquistadores, quienes quebraron templos e ídolos "como cosa de paso", sin lograr que los indígenas abandonasen sus costumbres. Aquí, la idolatría es desarraigada de los corazones a partir de la exposición de una verdad sostenible y no de una simple damnatio memoriae. Y los argumentos utilizados para sustentar dicha verdad, diversos y distantes en el tiempo, evidenciarán los múltiples rostros del evemerismo, las expresiones de un recurso polémico de notoria estabilidad en la historia de la misión. 